\title{
Abdominal Wall Reconstruction Utilizing the Component Separation Technique: Does Reinforcing Mesh Reduce Recurrences?
}

\author{
J Scott Roth*, Dennis F Diaz, Margaret Plymale and Daniel L Davenport
}

Department of Surgery, University of Kentucky College of Medicine, Lexington, USA

\begin{abstract}
Purpose: The component separation technique was initially described as an autologous tissue transfer without biomaterials. This study evaluates the results of component separation hernia with and without reinforcing mesh.

Methods: We retrospectively reviewed 126 consecutive component separation hernia repairs at a single institution between 2004 and 2009 and compared preoperative characteristics and postoperative outcomes.

Results: The recurrence rate was $20.6 \%$ and wound complications occurred in $46 \%$. Body mass index was associated with postoperative wound complications (non-obese $31.3 \%$, overweight $31.8 \%$, obesity/morbid obesity $51 \%$, superobese $69 \%$ ) but did not impact hernia recurrence rates (non-obese $7 \%$; overweight $12.5 \%$; obesity/morbid obesity $28.8 \%$, super obese, $23.2 \% ; p=0.207$ ). Gender, diabetes, hypertension, pulmonary disease, and smoking status did not impact recurrence rate or wound complications. Prior hernia repairs did not impact recurrence rates (none, 17\%; 1, 26.7\%, 2+, 23.1\%; $p=0.589$ ). 58 underwent repair without mesh, 55 with biologic mesh, and 13 with synthetic mesh. There were no differences in recurrences between groups.
\end{abstract}

Conclusion: Obesity significantly increases wound complications following CST hernia repair. Recurrence rates following primary and recurrent hernia repairs are similar. The adjunct of reinforcing mesh does not affect recurrence rates following CST.

Keywords: Hernia repair; Biologic mesh; Components separation technique; Recurrence rate

\section{Introduction}

Ventral incisional hernias are a common surgical problem occurring in $11-20 \%$ of patients undergoing laparotomy [1,2]. Many techniques have been described for repair of these hernias. Primary suture based repair is associated with a high incidence of recurrence. The utilization of mesh for hernia repair has substantially improved recurrence rates [3]. Laparoscopic hernia repairs are associated with low recurrence rates, low infection rates, and shorter hospital stays [4,5]. However, laparoscopic hernia repair is not feasible in all patient populations, particularly those with loss of abdominal domain, infection or abdominal contamination.

The Component Separation Technique (CST), as described by Ramirez and coworkers [6], may be used to reconstruct the abdominal wall without the need for a synthetic mesh. The technique allows for autologous tissue transfer, approximation of the rectus abdominis muscle complex, and closure of the linea alba following bilateral release of the external oblique aponeurosis and posterior rectus sheath. Recurrence rates with this technique have been reported as low as $18 \%$ [7].

While the CST was described without the additional utilization of bioprosthetic meshes, meshes are frequently used an adjunctive reinforcement to a ventral hernia repair. The use of a mesh as a reinforcement to a component separation hernia repair has been shown to both reduce $[8,9]$ and increase recurrence rates $[10,11]$. This study evaluates the outcomes of CST over a five-year period of time at a single institution.

\section{Methods}

After Institutional Review Board approval, the surgical database at the University of Kentucky was queried to identify patients who had undergone ventral incisional hernia repair with CST from 20042009. Patients were identified who had undergone procedures utilizing Current Procedure Terminology (CPT) codes 49560, 49561, 49565, or
49566 simultaneously with 15734 . Operative reports were reviewed to identify cases in which biologic or synthetic mesh was used as an adjunct to hernia repair with CST. Records were reviewed to obtain demographic data, preoperative co-morbid conditions, complications, and recurrences. Wound complications were defined as wound infection, wound necrosis, abscess, seroma requiring drainage, and cellulitis. Recurrence information was obtained from chart documentation of a hernia on physical examination or abdominal CT scan when available. Statistical analysis was performed utilizing T-test, chi square test, Fisher's exact test, or ANOVA where applicable.

\section{Results}

One-hundred-twenty-six patients were identified who underwent incisional hernia repair with CST. Median follow-up was 15.6 months (1-36 month range). The overall recurrence rate was $20.6 \%$. Wound complications were seen in $46 \%$ of patients. The incidence of wound complications was unaffected by age, gender, diabetes, hypertension, pulmonary compromise, or smoking status. Increased body mass index was associated with an increase in wound complications (Figure 1). The number of prior hernia repairs, the addition of a procedure other than hernia repair, the finding of an incarcerated hernia, the use of mesh, and the preoperative wound classification did not impact the incidence of postoperative wound complications. The incidence of hernia recurrence was not affected by age, gender, diabetes, hypertension,

*Corresponding author: J Scott Roth, Department of Surgery, University of Kentucky Medical Center, 800 Rose Street, C-226 UKMC, Lexington, KY 40536 USA, Tel: 859-323-6346; Fax: 859-323-6840; E-mail: jsroth2@uky.edu

Received November 20, 2012; Accepted April 26, 2013; Published May 07, 2013

Citation: Scott Roth J, Diaz DF, Plymale M, Davenport DL (2013) Abdominal Wal Reconstruction Utilizing the Component Separation Technique: Does Reinforcing Mesh Reduce Recurrences? Surgery Curr Res 3: 129. doi:10.4172/21611076.1000129

Copyright: (c) 2013 Scott Roth J, et al. This is an open-access article distributed under the terms of the Creative Commons Attribution License, which permits unrestricted use, distribution, and reproduction in any medium, provided the original author and source are credited. 


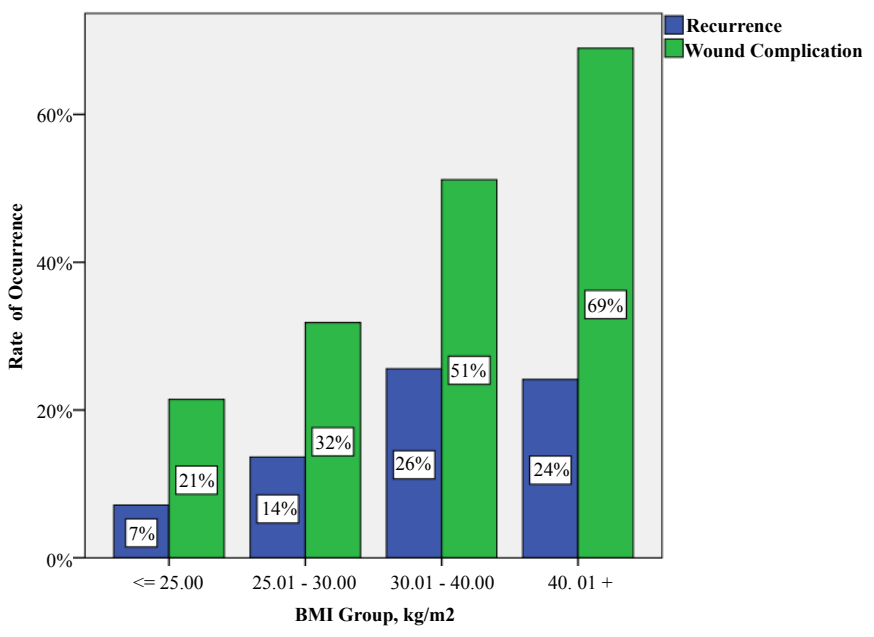

Figure 1: Wound complication and recurrence rates by BMI group.

pulmonary disease, smoking status, Body Mass Index (BMI), number of prior hernia repairs, wound classification, or adjunctive use of mesh (Table 1). Wound complications ( $\mathrm{p}=0.123$ ) developed in $39.6 \%$ of initial hernia repairs, $51.9 \%$ of singly recurrent hernia repairs, and $64 \%$ of multiple recurrent hernia repairs. The recurrence rates between initial (17.3\%), recurrent (26.7\%), and multiple recurrent hernia repairs (23.1\%) were similar (Figure 2). Multivariate regression demonstrated an increased risk for wound complications based upon BMI greater than $40.0 \mathrm{~kg} / \mathrm{m}^{2}$ and a decreased incidence of wound complications with increasing age (Table 2). Fifty-eight patients underwent CST without mesh, 55 patients underwent CST with biologic mesh, and 13 underwent CST with synthetic mesh. There were no differences in preoperative demographics or co-morbidities among the three groups (Table 3).

The preoperative wound classification was significantly different among groups with fewer contaminated cases in the group undergoing CST with synthetic mesh. Larger mesh sizes were utilized in the group undergoing CST with synthetic mesh than in the group undergoing CST with biologic mesh. Concomitant procedures were more commonly performed in the groups undergoing CST alone or CST with biologic mesh. No patients undergoing CST with synthetic mesh underwent additional concomitant procedures (Table 4). There were no differences in total wound complications, postoperative seromas requiring percutaneous drainage, wound infections, or wound necrosis between groups. Hernia recurrence rates were similar between CST, CST with biologic mesh, and CST with synthetic mesh.

\section{Discussion}

Wound complications following CST hernia repair occur not infrequently and are a significant source of postoperative morbidity in this patient population. In a prospective trial comparing CST to prosthetic repair, de Vries Reilingh [12] noted a 52\% wound complication rate in patients undergoing CST for large noncontaminated hernias. In this study, the risk of wound complications in clean hernia repairs was $40 \%$. The large dissection required for CST results in significant postoperative wound complications such as necrosis, abscess, infection, and seromas. The incidence of wound complications in contaminated and clean-contaminated procedures was not statistically different, although it trended toward a higher rate of wound complications as compared to clean procedures. Obesity was significantly associated with increased risk of wound complications.
Those patients with a BMI in excess of $40 \mathrm{~kg} / \mathrm{m}^{2}$ experienced wound complications more than twice as frequently as those patients with a BMI less than $30 \mathrm{~kg} / \mathrm{m}^{2}$. Quantifying the risk for wound complications following hernia repairs in obese patients allows for surgeons and patients to appreciate the importance of weight optimization prior to elective hernia repair in those patients with minimally symptomatic hernias. In our study, an increase in wound complications is seen with each successive hernia repair, with those undergoing 2 or more repairs having a risk of complications more than $50 \%$ greater than those undergoing first time repair. Although statistically insignificant, this trend is noteworthy and may be related to the relative ischemia of the abdominal wall associated with the prior operations. In our study, active smokers did not have an increased incidence of wound complications contradictory to other reports [13]. However, the benefits of preoperative smoking cessation prior to elective surgery have been clearly documented [14].

Recurrence rates following CST hernia repairs are reported to

\begin{tabular}{|c|c|c|c|c|c|}
\hline \multirow{2}{*}{$\begin{array}{l}\text { Variable } \\
\text { All Repairs w/ CST }\end{array}$} & \multirow[t]{2}{*}{\begin{tabular}{|c|} 
Incidence \\
$(\%)$
\end{tabular}} & \multicolumn{2}{|c|}{$\begin{array}{c}\text { Wound Complication, } \\
\% \text { P-Value* }\end{array}$} & \multicolumn{2}{|c|}{$\begin{array}{l}\text { Recurrence, } \% \\
\text { p-Value }\end{array}$} \\
\hline & & 46.0 & & 20.6 & \\
\hline Age $\leq 50$ y & 51.7 & 59.6 & 0.069 & 23.8 & 0.659 \\
\hline vs. age $>50$ y & 48.3 & 40.4 & & 19.3 & \\
\hline Female & 56.8 & 52.2 & 0.463 & 22.4 & 1.000 \\
\hline vs. male & 43.2 & 45.1 & & 20.8 & \\
\hline Diabetes & 23.7 & 57.1 & 0.390 & 16.7 & 0.610 \\
\hline vs. none & 76.3 & 46.7 & & 23.3 & \\
\hline Hypertension & 57.6 & 55.9 & 0.097 & 25.7 & 0.263 \\
\hline vs. not & 42.4 & 40.0 & & 16.0 & \\
\hline Pulmonary Compromise & 19.5 & 56.5 & 0.490 & 30.4 & 0.269 \\
\hline vs. not & 80.5 & 47.4 & & 19.6 & \\
\hline Active smokers & 38.1 & 51.1 & 0.850 & 27.1 & 0.264 \\
\hline vs. non-smokers & 61.9 & 47.9 & & 18.1 & \\
\hline BMI Group & & & 0.025 & & 0.207 \\
\hline$\leq 25 \mathrm{~kg} / \mathrm{m}^{2}$ & 13.6 & 31.3 & & 7.1 & \\
\hline $25.1-30.0 \mathrm{~kg} / \mathrm{m}^{2}$ & 18.6 & 31.8 & & 12.5 & \\
\hline $30.1-40.0 \mathrm{~kg} / \mathrm{m}^{2}$ & 43.2 & 51.0 & & 28.8 & \\
\hline$>40.0 \mathrm{~kg} / \mathrm{m}^{2}$ & 24.6 & 69.0 & & 23.3 & \\
\hline Concomitant Procedure & & & 0.219 & & 0.972 \\
\hline None & 63.6 & 48.0 & & 21.5 & \\
\hline Panniculectomy & 12.7 & 33.3 & & 20.0 & \\
\hline Gastrointestinal & 23.7 & 60.7 & & 23.1 & \\
\hline No. of Previous Repairs & & & 0.123 & & 0.589 \\
\hline None & 50.5 & 39.6 & & 17.3 & \\
\hline 1 & 25.7 & 51.9 & & 26.7 & \\
\hline $2+$ & 23.8 & 64.0 & & 23.1 & \\
\hline $\begin{array}{l}\text { Incarcerated/ } \\
\text { Strangulated }\end{array}$ & 44.1 & 53.8 & 0.458 & 25.0 & 0.506 \\
\hline vs. reducible & 55.9 & 45.5 & & 18.8 & \\
\hline Mesh Type & & & 0.524 & & 0.481 \\
\hline None & 46.6 & 54.5 & & 25.5 & \\
\hline Biologic Mesh & 44.9 & 45.3 & & 16.7 & \\
\hline Synthetic Mesh & 8.5 & 40.0 & & 27.3 & \\
\hline Wound Class & & & 0.080 & & 0.599 \\
\hline Clean & 63.8 & 40.5 & & 24.0 & \\
\hline Clean/Contaminated & 10.3 & 66.7 & & 10.0 & \\
\hline Contaminated & 25.9 & 60.0 & & 21.2 & \\
\hline
\end{tabular}

${ }^{*} \mathrm{P}$-value is from Fisher's Exact test for binary variables and chi-square test for categorical variables. [CST=Component Separation Technique; BMI=Body Mass Index]

Table 1: Wound complication and recurrence rates by patient and operative risk factors. 


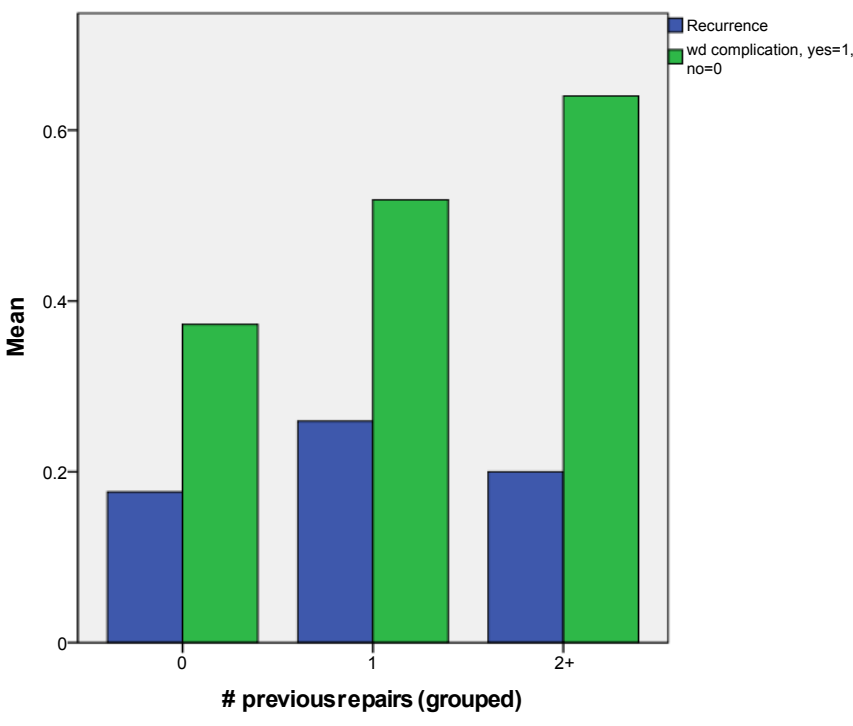

Figure 2: Recurrence and wound complication rates per number of previous repairs.

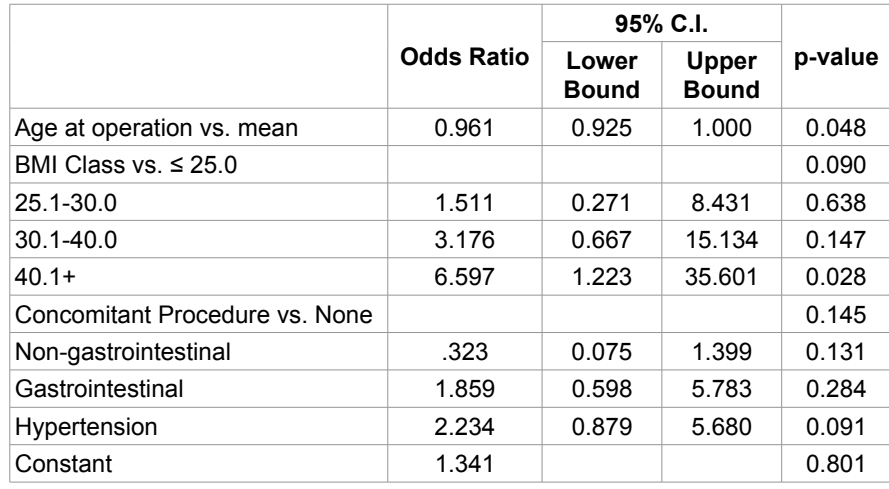

C.I. $=$ Confidence Interval; BMI=Body Mass Index

Table 2: Independent predictors of any wound infection in patients undergoing incisional hernia repair with component separation. Results from forward stepwise multivariable regression, $p$ for entry $<0.20$ and for exit $>0.25 \mathrm{~N}=105$ due to missing variables, number of wound infections $=51$.

occur in up to $52 \%$ of patients [12]. The technique of CST was initially described as a method for repairing larger hernias without the need for a prosthetic material [6]. The practice of reinforcing CST hernia repairs with mesh is performed not uncommonly despite the conflicting evidence. The use of biologic mesh as a reinforcement to CST hernia repair has been shown to reduce the risk of hernia recurrence from $20 \%$ of unreinforced CST hernia repairs to $5 \%$ with the adjunct of biologic mesh [8]. However, a more recent study of 200 CST hernia repairs demonstrated an increased risk of hernia recurrence with the use of biologic mesh relative to an unreinforced repair [11]. The aforementioned study demonstrated the lowest recurrence rate in a group undergoing CST hernia repair with soft polypropylene mesh. In the current study, the overall recurrence rate for primary component separation was $20.6 \%$, consistent with other reports [6-11]. We were unable to demonstrate a significant difference in hernia recurrence rates between CST alone, CST with biologic mesh or CST with synthetic mesh with a mean follow up of 16 months. This is in contrast to ventral hernia repairs performed without the utilization of CST in which the recurrence rates without the utilization of mesh are significantly higher $[3,15]$. While the cohort undergoing component separation without mesh had similar demographics as those undergoing component separations with either mesh type, a selection bias may account for the differences in recurrences between those who underwent repair with and without mesh materials. Additionally, there does not appear to be a detriment, aside from cost, to the adjunctive use of mesh, as the incidence of complications was similar between CST hernia repairs performed with or without mesh and no patients required mesh excision. The authors remain convinced that there is a benefit to reinforcing CST hernia repairs with mesh.

In this study, we attempted to identify patient co-morbidities and

\begin{tabular}{|c|c|c|c|c|}
\hline Variable & $\begin{array}{l}\text { CST w/o } \\
\text { Mesh }\end{array}$ & $\begin{array}{c}\text { CST w/ Biologic } \\
\text { Mesh }\end{array}$ & $\begin{array}{c}\text { CST wl } \\
\text { Synthetic } \\
\text { Mesh }\end{array}$ & p-value* \\
\hline No. of Cases & 58 & 55 & 13 & \\
\hline Age (Mean y \pm S.D.) & $49.3 \pm 12.4$ & $50.2 \pm 12.4$ & $52.1 \pm 9.9$ & 0.750 \\
\hline Female, \% & 65.5 & 45.5 & 53.8 & 0.099 \\
\hline BMI Group, $\%, n=117^{\dagger}$ & & & & 0.117 \\
\hline$\leq 25 \mathrm{~kg} / \mathrm{m}^{2}$ & 7.4 & 21.6 & 8.3 & \\
\hline $25.1-30.0$ & 25.9 & 11.8 & 41.7 & \\
\hline $30.1-40.0$ & 42.6 & 37.3 & 33.3 & \\
\hline $40.1+$ & 24.1 & 29.4 & 16.7 & \\
\hline Hx Diabetes, $n=118^{\dagger}$ & 22.8 & 36.0 & 9.1 & 0.114 \\
\hline Hx Hypertension, $n=124^{\dagger}$ & 63.2 & 53.7 & 76.9 & 0.262 \\
\hline $\begin{array}{l}\text { Pulmonary Compromise }{ }^{\ddagger}, \\
n=116^{\dagger}\end{array}$ & 16.0 & 23.6 & 45.5 & 0.101 \\
\hline $\mathrm{Hx}$ Smoking, $\mathrm{n}=96^{\dagger}$ & 54.3 & 48.8 & 55.6 & 0.853 \\
\hline
\end{tabular}

*P-value is for ANOVA of age differences and chi-square test for other variables 'Some missing values in patient characteristics. ${ }^{\dagger}$ Pulmonary compromise included chronic obstructive pulmonary disease, emphysema, or asthma. [CST=Component Separation Technique; S.D.=Standard Deviation; BMI=Body Mass Index; $\mathrm{Hx}=$ History]

Table 3: Characteristics of patients undergoing component separation.

\begin{tabular}{|c|c|c|c|c|}
\hline Variable & $\begin{array}{l}\text { CST w/o } \\
\text { Mesh }\end{array}$ & $\begin{array}{c}\text { CST w/ Biologic } \\
\text { Mesh }\end{array}$ & $\begin{array}{l}\text { CST wl } \\
\text { Synthetic } \\
\text { Mesh }\end{array}$ & P-value* \\
\hline No. of Cases & 58 & 55 & 13 & \\
\hline $\begin{array}{l}\text { Incarcerated/ } \\
\text { Strangulated, \% }\end{array}$ & 48.3 & 45.5 & 30.8 & 0.518 \\
\hline Prior Repairs, \% & & & & 0.302 \\
\hline None & 49.1 & 50.0 & 36.4 & \\
\hline 1 & 26.4 & 22.9 & 54.5 & \\
\hline $2+$ & 24.5 & 27.1 & 9.1 & \\
\hline Concomitant Procedure & & & & 0.002 \\
\hline None & 74.1 & 47.3 & 100.0 & \\
\hline Non-Gastrointestinal & 8.6 & 20.0 & 0.0 & \\
\hline Gastrointestinal & 17.2 & 32.7 & 0.0 & \\
\hline $\begin{array}{l}\text { Size of Mesh, } \mathrm{cm}^{2} \\
\text { mean } \pm \text { s.d., } \mathrm{n}=51^{\dagger}\end{array}$ & $\mathrm{n} / \mathrm{a}$ & $301 \pm 131$ & $447 \pm 208$ & 0.039 \\
\hline Wound Class & & & & 0.050 \\
\hline Clean & 66.7 & 50.0 & 92.3 & \\
\hline Clean/Contaminated & 10.5 & 11.1 & 0.0 & \\
\hline Contaminated & 22.8 & 38.9 & 7.7 & \\
\hline Wound Complication & & & & 0.644 \\
\hline Seroma & 3.7 & 7.5 & 10.0 & \\
\hline Infection/Necrosis & 50.0 & 39.6 & 30.0 & \\
\hline Recurrence & 25.5 & 16.7 & 27.3 & 0.481 \\
\hline
\end{tabular}

${ }^{*} \mathrm{P}$-value is for ANOVA of age differences, T-test of mesh size differences, and chi-square test for other variables; ${ }^{\dagger}$ Some missing values in mesh size. $\neq$ Pulmonary compromise included chronic obstructive pulmonary disease, emphysema, or asthma.

Table 4: Operative characteristics and outcomes of patients undergoing component separation. 
hernia characteristics that were risk factors for hernia recurrence. The influence of chronic illness, obesity, and type of repair on the likelihood of recurrence following elective midline hernia repair has previously been shown to be non-correlative [16-18]. Other reports have demonstrated age, male gender, and smoking status as being associated with increased risks of hernia recurrence [19]. In our study, we were unable to demonstrate an increase in hernia recurrence rates based on age, diabetes, hypertension, pulmonary disease, or smoking status. In our study, underweight $(\mathrm{BMI}<18.5)$ and overweight $(\mathrm{BMI}$ 25-30) patients developed fewer recurrences than obese or morbidly obese patients. Although this did not reach statistical significance, there is a trend toward an increased risk of hernia recurrences in the obese population. Prior studies have demonstrated an increased risk of hernia recurrence in patients in which the ideal body weight exceeds $120 \%[16]$.

In a retrospective study of patients undergoing incisional hernia repair, Flum et al. [15], noted a $23.8 \%$ reoperation rate following initial hernia repair, and subsequent repairs further increased the risk of recurrence to $35.3 \%$ after a second repair and $38.7 \%$ after a third repair. In our study, recurrence rates for patients undergoing hernia repair by means of CST were not statistically different between first time hernia repairs, second time hernia repairs, and those who had undergone more than two prior repairs (Figure 2). This suggests that CST hernia repair may offer an advantage compared to synthetic mesh-based hernia repairs for recurrent hernias in that the recurrence rates seems to not be affected by the number of prior repairs. However, larger prospective trials would need to be performed to confirm this hypothesis.

\section{Conclusions}

The CST allows for an autologous tissue based hernia repair in complex hernia patients. Wound complications following CST occur not infrequently and are increased in patients with obesity. Hernia recurrence rates following CST occur in an acceptable number of patients and are similar between primary, recurrent, and multiply recurrent hernia repairs, suggesting that CST hernia repair may offer the greatest advantage in the recurrent hernia population. Reinforcing CST hernia repairs with either biologic or synthetic mesh has no proven advantage over an unreinforced repair. Prospective studies controlling for both hernia characteristics and patient factors are needed to identify those patient populations that will benefit most from CST hernia repairs.

\section{References}

1. Mudge M, Hughes LE (1985) Incisional hernia: a 10 year prospective study of incidence and attitudes. Br J Surg 72: 70-71.

2. Cengiz Y, Israelsson LA (1998) Incisional hernias in midline incisions: an eightyear follow up. Hernia 2:175-177.

3. Luijendijk RW, Hop WC, van den Tol MP, de Lange DC, Braaksma MM, et al.
(2000) A comparison of suture repair with mesh repair for incisional hernia. N Engl J Med 343: 392-398.

4. Heniford BT, Park A, Ramshaw BJ, Voeller G (2003) Laparoscopic repair of ventral hernias: nine years' experience with 850 consecutive hernias. Ann Surg 238: 391-399.

5. Toy FK, Bailey RW, Carey S, Chappuis CW, Gagner M, et al. (1998) Prospective, multicenter study of laparoscopic ventral hernioplasty. Preliminary results. Surg Endosc 12: 955-959.

6. Ramirez OM, Ruas E, Dellon AL (1990) "Components separation" method for closure of abdominal-wall defects: an anatomic and clinical study. Plast Reconstr Surg 86: 519-526.

7. de Vries Reilingh TS, Bodegom ME, van Goor H, Hartman EH, van der Wilt $\mathrm{GJ}$, et al. (2007) Autologous tissue repair of large abdominal wall defects. $\mathrm{Br}$ Surg 94: 791-803.

8. Espinosa-de-los-Monteros A, de la Torre JI, Marrero I, Andrades P, Davis MR et al. (2007) Utilization of human cadaveric acellular dermis for abdominal hernia reconstruction. Ann Plast Surg 58: 264-267.

9. Buinewicz B, Rosen B (2004) Acellular cadaveric dermis (AlloDerm): a new alternative for abdominal hernia repair. Ann Plast Surg 52: 188-194.

10. de Vries Reilingh TS, van Goor H, Rosman C, Bemelmans MH, de Jong D, et al. (2003) "Components separation technique" for the repair of large abdomina wall hernias. J Am Coll Surg 196: 32-37.

11. Ko JH, Wang EC, Salvay DM, Paul BC, Dumanian GA (2009) Abdominal wall reconstruction: lessons learned from 200 "components separation" procedures. Arch Surg 144: 1047-1055

12. de Vries Reilingh TS, van Goor H, Charbon JA, Rosman C, Hesselink EJ, van der Wilt GJ, Bleichrodt RP (2007) Repair of giant midline abdominal wall hernias: "Components Separation Technique" versus prosthetic repair interim analysis of a randomized controlled trial. World J Surg 31:756-763.

13. Finan KR, Vick CC, Kiefe Cl, Neumayer L, Hawn MT (2005) Predictors of wound infection in ventral hernia repair. Am J Surg 190: 676-681.

14. Theadom A, Cropley M (2006) Effects of preoperative smoking cessation on the incidence and risk of intraoperative and postoperative complications in adult smokers: a systematic review. Tob Control 15: 352-358.

15. Flum DR, Horvath K, Koepsell T (2003) Have outcomes of incisional hernia repair improved with time? A population-based analysis. Ann Surg 237: 129135

16. Anthony T, Bergen PC, Kim LT, Henderson M, Fahey T, et al. (2000) Factors affecting recurrence following incisional herniorrhaphy. World J Surg 24: 95100

17. Hesselink VJ, Luijendijk RW, de Wilt JH, Heide R, Jeekel J (1993) An evaluation of risk factors in incisional hernia recurrence. Surg Gynecol Obstet 176: 228 234.

18. van der Linden FT, van Vroonhoven TJ (1988) Long-term results after surgical correction of incisional hernia. Neth J Surg 40: 127-129.

19. Sørensen LT, Hemmingsen UB, Kirkeby LT, Kallehave F, Jørgensen LN (2005) Smoking is a risk factor for incisional hernia. Arch Surg 140: 119-123. 